\title{
Causes of Relapse into Illiteracy of Adult Female Neo-Literates: An Evaluation
}

\author{
Asaf Niwaz \\ Aftab Ahmed ${ }^{* *}$ \\ Amir Zaman ${ }^{* * *}$
}

\begin{abstract}
The present study was designed to explore the factors that responsible for the relapse into basic literacy skills of adult neo-literates. This qualitative study utilized strategies, including: a survey, interviews, focused group discussions, artifacts, and observations. Random and criterion sampling techniques were applied. The data was analyzed by sorting, coding, and categorizing the views of the respondents. The study explored these three problems areas: the implementation of a literacy program, addressing the needs and aspirations of adult female neo-literates and the teachers' delivery of the courses. The results of this inquiry identified key factors tied to the three problem areas: the teachers were inadequately trained and failed to observe the basic standards of courtesy and respect for the learners. The courses ran at inappropriate times, were too short and used inadequate accommodation. While not excessively difficult, the materials used were not related to the real needs of the learners who wished, in the main, for literacy skills in relation to income generating activities. There was a need for increased opportunities to practise the skills taught and follow up courses were required.
\end{abstract}

Keywords: Neo-literates, adult literacy, assessment, teachers, supervisors, basic literacy skills.

\footnotetext{
* Assistant Professor, University of Haripur, Pakistan. Corresponding author: Email: dr.ansatti75@gmail.com

${ }^{* *}$ Lecturer, Allama Iqbal Open University, Islamabad

${ }^{* * *}$ Assistant Professor, Abdul Wali Khan University, Mardan
} 


\section{Introduction}

Adult learners possess specific interests, needs, experiences, desires, and motivations. The learning processes of adult learners are unique and different from the learning processes of children on the basis of the specific characteristics e.g., experienced, involve in purposeful activities, self-motivated, and high expectations. (Vodde, 2008) . Adults, generally, learn better in an environment where they feel their self-respect is guaranteed as independent learners (Rogers, 2002).The word "relapse" means, to fall or slide back into a former state. In the field of education, Relapse means forgetting the skills one learned in formal or non-formal educational settings. A relapse in adult literacy programs means the partial or complete regression into illiteracy in reading, writing, and arithmetic skills to the previous neo-literate state. A neo-literate in adult literacy programmes means a person who completed his/her basic literacy course irrespective of time (earlier time which has passed after having literacy training). Researchers and scholars Guodeng and Zhang (2003), Abadzi, (2003b) and Comings, (1995) in the field of literacy suggest that further learning opportunities for neo-literates to consolidate and strengthen their previously learned skills of reading, writing, and arithmetic need to be provided. Kothari, Takeda, Joshi and Pandey, 2003) reported that, in India, the National Literacy Mission (NLM) has contributed significantly in increasing the number of adult literates through adult literacy programs, but its post-literacy programs have not been able to tackle the serious problem of the relapse into illiteracy of adults. Surakhmad, (2009) also says, people forget things they study including literacy skills if they do not practice it.

Research studies such as those of (Adeeb, 2007; Nisa, 2008) highlighted this phenomenon of relapse as a huge waste of resources in adult literacy programs in Pakistan. According to Abadzi (2003a), The World Bank financed some literacy projects from 1963 to 1985 in the countries such as Yemen, Somalia, Afghanistan, Ethiopia and Malawi, the overall efficiency of these adult literacy programs was only considered to be $12.5 \%$. Abadzi (2004) also examined available data on 32 literacy projects financed by different donors and reported that the pass rate of a final test was 56 per cent. According to Cawthera, (2003) in Bangladesh, 19 neo-literates were assessed after three years of their study in literacy centers. The results suggested no relapse in basic literacy skills because there were variety of topic to study and duration was more than a year. 


\section{Theoretical Lens}

In Pakistan, the main purpose of launching adult literacy program is to make the illiterate into self-directed learners. Among all theories addressing self-directed learning andragogy is the most prominent, that is why it has been chosen as the theoretical lens of this study. Merriam (2001) explained that scholarship through andragogy is one of the two major pillars of adult learning research and theory; according to St.Clair (2002) andragogy is one theory for the 21 st century that will maintain its role as a necessary component of the field's shared knowledge; Monts (2000) articulates the need for basic instruction of both teachers and students through andragogy; and Akande and Jegede (2004) hold that andragogy is one of the new sciences of education that is now gaining ground in many areas of study. Knowles (1975) defines self-directed learning as a process in which individuals take the initiative, without the help of others. The present study was about adult female learners in adult literacy in Pakistan because most organizations launch female literacy programs to minimize the gender gap in literacy.

\section{Principles of Adult Learning}

Knowles (1998) has suggested that much can and has been learned by examining principles and practices of andragogy. Comparing such practices to traditional pedagogical methods, Knowles sets forth six theoretical assumptions about adult learners which he espouses as principles of practice that serve to facilitate adult learning. Knowles' andragogical assumptions about adult learning are as follows:

1. Adult learners need to know why to learn before involving themselves in the learning process. A better understanding of the whole teaching learning process increases motivation, interest, performance, attendance, and success;

2. They think themselves responsible and capable of making good decisions at proper times and wish to be treated as adults. They strongly resent and resist authority in situations where they feel that others are imposing their will on them;

3. Knowles noted that the interests, motivations, learning styles, and goals of adult learners have serious implications for adult learning compared to children;

4. According to Vodde (2008), adult learners become ready to learn those things which they need to know and enable them to cope with real life situation effectively. Rich source of readiness to learn are 
developmental tasks associated with moving from one developmental stage to the next;

5. In contrast to children's and youth's subject centered orientation to learning, adults are life centered (task centered or problem centered) in their orientation to learning (Vodde, 2008; Knowles, 1998) and;

6. According to Tough (1978, cited by Vodde, 2008), all normal adult learners are motivated to keep growing and developing, but this motivation is blocked by factors like poor self-concept as learner, lack of opportunities to learn, and inaccessibility to learning due to time constraints (as in female adult literacy programs) and programs that are not designed according to the principles of adult learning. Holton, Swanson, and Naquin (2001) citing Davenport and Davenport, (1995), Hartree, 1984, and Pratt, 1988, stated that though andragogy has been criticized by many scholars, the core principles of adult learning progressed and advanced by andragogy have endured. The six principles of adult learning are applicable and valuable to adult literacy teachers. The change agents and can bridge the gap between theory and practice. In the preparation or training for teachers, andragogical principles should be kept in mind in the content of teachers training of adult literacy programs.

\section{Process Model of Andragogy}

Vodde (2008, cited Knowles, 1998) said the pedagogical model emphasized content while the andragogical model was based on a process design. In a process design, the role of teachers, facilitators/instructors is dual in nature: 1) to serve as a the designer and manager of processes and procedures in order to facilitate the acquisition of content, and (2) to serve as a content resource with the provision of support material, media resources, field experiences, to seek the assistance of peers and other individuals who have specialized knowledge and skills. According to Holton, Swanson and Naquin (2001), the steps of the andragogical process designed by Knowles have generated effective adult learning experiences. Similarly Knowles (1989) himself stated that andragogy is less a theory than a model of assumptions about learning or a conceptual framework that serves as a basis for an emergent theory. The steps of the andragogical process design help maximum participation of adult learners which is a prominent aspect of self-directed learning. Whenever learners of any type have autonomy to choose what to learn and how to learn, their interest increases. 


\section{Method and Procedure}

The main purpose of the study was to explore factors affecting relapse into illiteracy of adult female neo-literates in Pakistan. A research question was also developed:

Why do adult female neo-literates relapse into illiteracy in basic skills of reading, writing and numeracy? Sub-questions include:

a). to what extent do teachers play a role in retention or relapse of basic literacy skills? b). to what extent do learners play a role in retention or relapse of basic literacy skills? c). to what extent does the content of adult literacy programs play a role in retention or relapse of basic literacy skills? d). to what extent does timing of classes play a role in retention or relapse of basic literacy skills? e). to what extent does the duration of adult literacy program play a role in retention or relapse of basic literacy skills? f). to what extent does the gap of the study play a role in retention or relapse of basic literacy skills?

The present study was qualitative in orientation. This qualitative study utilized strategies, including: a survey interviews, focused group discussions, artifacts and observations. The sample of the study was selected in two phases with random sampling technique. Firstly, 240 adult female neo-literates, 90 teachers of adult literacy programs, 60 supervisors of adult literacy programs, and 18 officials (higher management of the organization and heads of education department at district level) were selected from 6 out of 35 districts of the Punjab province. From each sample district, 40 adult female neo-literates, 15 adult literacy teachers, 10 literacy supervisors, an Executive District Officer (EDO), a District Literacy Officer (DLO), and the Head of a local Non-government Organization (NGO) were selected. In the second phase, a total of 48 respondents including 18 female neo-literates, 12 adult literacy teachers, 12 literacy supervisors, and 6 social workers were selected. The major criteria used in the selection of participants in the second phase were they were from different communities and they were not acquainted with one another, though all had similar jobs in the selected organizations. Adult female learners were of different age groups, teachers of adult literacy, and supervisors of adult literacy programs who had different qualifications and experience, and the social workers who were actively involved in adult literacy programs as community representatives. In each of the focus discussion groups (FGDs) 3 adult female neo-literates, 2 adult literacy teachers, 2 literacy supervisors, and 1 social worker were selected. Six FGDs (one in each of 
sample district) were arranged and conducted with the help of the local NGOs and female research assistants.

Four separate but similar interview protocols were constructed for adult female neo-literates, literacy teachers, literacy supervisors, and officials. Questions of the interview protocols were developed to evaluate the role of teachers, learners, content of literacy programs, timing of the literacy classes, gap of the study (the actual time that had passed since their graduation from basic adult literacy programs), and the duration of adult literacy programs. Interview for female learners were in very simple in language (according to their level of education) as compared to the questions of other interview protocols of teachers, supervisors, and officials. The research instruments (interview protocols) were pilot tested in order to ensure their validity and the experts of adult literacy and directors/national managers of these organizations were consulted. Officials were interviewed first, then teachers and supervisors, and then female neo-literates in an attempt to understand the situation. Lastly, focused group discussion (FGDs) were arranged and conducted to explore what learning took place in the adult literacy centers. This FGDs technique was used to get more understanding about the factors which contributed in relapse of basic literacy skills of adult learners. Data from female neo-literates, teachers, and supervisors were recorded on digital camera during the discussion groups with the help of female research assistants. The data from officials were collected personally by the author. A chart reflecting all elements of the study (teachers, learners, content, timing, gap of the study, and duration) was designed and the responses were added against each heading and subheading of these specific areas of investigation. The responses were sorted, coded, and categorized to try to answer the research questions. After the data was placed appropriately, it was coded. An example of the coding process was that dominant responses to questions were given as Code 1 and responses with a secondary priority were given the Code 2 . The coding process (responses in relevant place) helped the researcher judge the response frequency in each interview category and to explore the realities that prevailed in the adult literacy programs.

\section{Results}

The following results of the study were based upon the data collected through interview and the FGDs. The results are organized in response to the research question and its six sub-questions. 


\section{Research Question 1}

a. To what extent do teachers play a role in retention or relapse of basic literacy skills?

The role of adult literacy teachers was not found satisfactory by most of the respondents in terms of conduct/behavior, encouragement and motivation for learners, individual attention rather favoring only few relatives or friends, regularity in taking classes, engaging sisters or friends as teachers, and registration of learners. Most of the teachers and supervisors were not trained properly in how to teach adult learners. Most of them were not interested in learning numeracy and the basic literacy skills of reading, and writing. Most of the participants wanted to learn skills which may enable them to earn money instead of having basic literacy skills. According to teachers and supervisors, neo-literates relapsed into illiteracy because learners were not regular in classes and they could not learn well in the class. It was, therefore, be concluded that when teachers are not trained and when they treat or deal with the learners unprofessionally, the learners would not find favorable place of learning. They will be irregular in their studies. Therefore good or positive results could not be expected.

\section{b. To what extent do learners play a role in retention or relapse of} basic literacy skills?

More than 60 per cent of adult female learners were not interested in learning basic skills in reading, writing and numeracy skills. Adult female neo-literates had been performing a variety of domestic duties as compared to young ones and they did not find enough time to learn or develop their interest in learning the basic skills. They could not master the basis literacy skills of reading, writing and numeracy in literacy classes and relapsed into illiteracy. A, one of the elder participants who was the resident of Dhoke (Village) Boota, the District of Attock, reported:

I was not regular like many other learners in literacy classes. We did not have much time to attend literacy classes and stayed there for two hours. We even could not spare time at home to practice whatever we learnt in literacy classes. We had a lot of work to do in fields, for our cattle, for children, and for other family members.

The role of elder adult female as learners was generally disappointing. They were irregular, they used to left literacy centers early, they were very busy in domestic tasks, and some were shy and did 
not participate actively. Another female learner, (approx. age 20 years) who was resident of Dhoke Lal Din, District Rawalpindi reported:

I was very regular learner in literacy classes. Our Baji (Elder sister, means teacher) was very happy with me. She used to help me whenever I went to her. She was my friend. I was interested to learn more, but we didn't have any such supporting situation for further learning.

c. Content of adult literacy programs and retention or relapse of literacy skills?

Irrelevance of content was one of the major causes of relapse. It was uninteresting and lacked utility in the everyday lives of the learners. One of adult female learners, who was an active learner of literacy center in village Basi of district Rawalpindi, said:

I successfully passed primary classes at my early age. I enrolled myself to learn sewing, knitting and embroidery in order to earn money. The organization did not offer this component of adult literacy programs as announced.

Most of the learners were enrolled to learn basic literacy skills but, the skills which enable learner to earn money like skills of sewing, knitting, and embroidery was not launched in the province due to unavailability of funds and proper infrastructure.

\section{d. Timing of classes play a role in retention or relapse of basic literacy skills}

Like many other learners, Farheen, reported:

I get up early in the morning in village. After doing some domestic work and breakfast, I usually reached in the fields before sun rises. I come back at lunch time. After having lunch, I take some rest and at that time it is not possible for me to go in literacy centre to attend classes. The timing of the class is very problematic for us.

For most of the respondents, the timing of the classes was not appropriate in summer. This was rest time in rural areas and rural people usually take rest at noon after doing a lot of hard work in the fields. Due to inappropriate timing, learners could not attend the classes regularly. They could not learn well, hence, relapsed into illiteracy. 


\section{e. Gap of the study play a role in retention or relapse of basic literacy skills}

When someone does not have an opportunity to strengthen his or her learned skills, there is a possibility of a relapse in or regression in literacy skills. Isfahana said:

I forgot how to read, write, and numerate because I haven't got opportunity to revise or practice basic skills of literacy for the last three years. I did not have any opportunity to learn basic skills of literacy properly because there was no continuation of literacy program.

All of the respondents reported that due to the unavailability of further opportunities to learn and discontinuity of learning program, they relapsed into illiteracy.

\section{f. Duration of literacy program play a role in retention or relapse of literacy skills?}

Less time in learning basic skills also played a role in the relapse of basic skills for neo-literates. To most of the respondents, the duration of 3 months was insufficient to learn the basic literacy skills well. Three books were offered for learning and Book 3, Roshan Rahian, was difficult to learn in a month. The majority of those in the 15 to 25 age group were of the view that 3 months was too short to learn these skills properly.

\section{Conclusions and Discussion}

The present study revealed that there were many factors that contributed to relapse of basic skills of adult female neo-literates in Pakistan. The role of the adult literacy teacher was significant and this finding was supported by Wagner (2000), who acknowledged that teachers play a significant role in the retention or relapse of basic literacy skills. According to National Commission for Human Development NCHD (2005), there was lack of motivation on the part of teachers and they were not motivating adult learners in the class. Rogers (2005) cited many researchers who acknowledged that the failure of adult literacy learning programs was often because teachers were untrained or inadequately trained.

The current inadequate training of instructors needs to be addressed urgently as does support for their professional performance through regular well-planned supervision. In addition to initial training, there should be refresher courses at six-month intervals after completion of cycle for 
improving practice. Adult literacy teachers behaved rudely with adult female learners in the classes. According to Knowles (1998), the psychological climate is more necessary for adult learning and it includes mutual respect, collaboration, trustworthiness, support, openness, and authenticity. Similarly, Rogers (2002) proposes that a positive and constructive learning climate in adult literacy classes has four characteristics, 1) warmth, 2) directness, 3) enthusiasm, and 4) organization.

The study also found that adult learners were not regular attendees and most of them were not interested in learning basic literacy skills, suggesting that simply learning how to read and write was not sufficient motive for them. Wagner (2000) argued that motivation of learners in adult literacy programs played a significant role in the retention or relapse of basic literacy skills. This fact was also highlighted by Abadzi (2003b), to him the retention of basic literacy skills depends upon their usage in everyday life. This finding is supported by Doronilla's (1996) assertion that knowledge with little or no utility in everyday life cannot be retained by adult learners. According to Abadzi (2003b), low quality of instruction plays a significant role in the relapse of basic literacy skills. Comings (1995), said that duration of adult literacy programs of 200 to 300 hours and less than one year of duration led to some relapse of literacy skills. It was found that the gap of study played a significant role in relapse of basic literacy skills in adult female neo-literates. This finding is supported by Guodeng and Zhang (2003).

The content of adult literacy programs was found to be uninteresting and irrelevant to the needs and aspirations of many of the adult female learners. This finding was supported by Abadzi (1995, 2003b) and Rogers (2002) who said that uninteresting content cannot yield better results in adult literacy programs. The findings of the present study also support the results of study by Guodeng and Zhang (2003) who investigated many factors that contributed in relapse on skills of adult neo-literates in China. There was also less support from family for education, a poor quality of teaching, a lack of motivation, inadequate teacher training, and monitoring issues. Comings (1995) highlighted some of the factors which play a role in relapse of literacy skills like, low quality of instructions in the centers, no prior schooling, and the nonavailability of post literacy programs. The Comings study in Uganda showed that learners with prior schooling retained basic literacy skills. 


\section{References}

Abadzi, H. (2004). Strategies and policies for literacy: Education for all global monitoring report 2006. Washington, D.C: Operations Evaluation Department

Abadzi, H. (1995). Difficulties of adults in the acquisition of reading skills: A review of the evidence. Paper presented at the Annual Meeting of the American Educational Research Association, San Francisco, CA.

Abadzi, H. (2003a). Improving adult literacy outcomes: Lessons from cognitive research for developing countries. Washington, D.C: Operations Evaluation Department.

Abadzi, H. (2003b). Teaching adults to read better and faster: Results from an experiment in Burkina Faso. Policy Research Working Paper Series: Washington, D.C.

Adeeb, A. (2007). Evaluation of retention level of Neo-literates in Pakistan. NCHD in collaboration of Asian development Bank, Pakistan.

Akande, J. O., \& Jegede, P. O. (2004). Andragogy and computer literacy: The Nigerian perspective. The African Symposium: An on-line educational research journal, 4(2).

Bingman, M. (2000). "I've come a long way." Learner-identifies outcomes of participation in literacy programs. NCALL, Report 13, 37-39.

Brookfield, S.D. (1986). Understanding and facilitating adult learning. San Francisco: Mc Graw Hill Education.

Burchfield, S., Hua, H., Iturry, T.S., \& Rocha, V. (2002). A longitudinal study of the effect of integrated literacy and basic education programs on the participation of women social and economic development in Bolivia. Washington D.C. 
Cawthera, A. (1999). Let's teach ourselves: A people's movement in Bangladesh. Manchester Monographs, Centre for Adult and Higher Education. England.

Cawthera, A., (2003). Nigira Shikhi and adult literacy: Impact on learners after five years. Effectiveness when operating as an NGO.

Comings, J. (1995). Literacy skill retention in adult students in developing countries. International Journal of Educational Development, 37-45.

Creswell, J. (2002). Research design: Qualitative, quantitative, and mixed methods approaches (2nd ed.). Thousand Oaks, CA: Sage Publications.

Dighe, A. (2004). Pedagogical approaches to literacy acquisition and effective programme design. Think-piece for EFA Global Monitoring Report 2006, 357.

Doronilla, M.L. (1996). Landscapes of literacy: An ethnographic study of functional literacy in marginal Philippine communities. UIEn

Egbo, B. (2000). Gender, literacy and life chances in sub-Saharan Africa. Cleveland, Buffalo, Sydney: Multilingual Matters.

Guodeng, X., \& Zhang Z. (2003). Meeting the basic learning needs of the newly literate: China's post literacy education for the early $21 \mathrm{st}$ century. International Review of Education, 49(6), 621-629.

Holton, E.F., Swanson, R.A., \& Naquin, S. (2001). Andragogy in practice: Clarifying the andragogical model of adult learning. Performance Improvement Quarterly, 14(1), 119-121.

Kagitcibasi, C.F., Goksen, \&. Gulgoz. (2005). Functional adult literacy and empowerment of women: Impact of a functional literacy program in Turkey. Journal of Adolescent and Adult literacy, 48(6), 478-481.

Knowles, M. (1975). Self-Directed Learning. Chicago: Follet. 
Knowles, M. S. (1989a). Adult learning: Theory \& practice. In L. \& Z. Nadler, (eds). The Handbook of Human Resource Development, Second Edition. New York: John Wiley \& Sons.

Knowles, M.S. (1984) Andragogy in action. San Francisco, CA: Jossy-Bass.

Knowles, M.S., Holton, E.F., and Swanson, R.A. (1998). The adult learners: The definitive classic in adult education and human resource development, (5th ed.).

Kothari, B., Takeda, J., Joshi, A., \& Pandey, A. (2003). Same Language Subtitling: A Butterfly for Literacy? Reading Beyond the Alphabet. SAGE Publishing

Lauglo, J. (2001). Engaging with adults: The case for increased support to adult basic education in sub-Saharan Africa. Africa Region. 271274.

Merriam, S. B. (2001). Andragogy and self-directed learning: Pillars of adult learning theory. The New Update on Adult Learning Theory. San Francisco: Jossey-Bass.

Monts, B. (2000). Andragogy or pedagogy: A discussion of instructional methodology for adult learners. Illinois State University. Unpublished paper.

NCHD. (2005). Training manual for district literacy coordinators. Islamabad.

Nisa, K. (2008). An evaluative study of non-formal and adult literacy centers of Balochistan and development of an action plan for the period 2010. (Unpublished Thesis).

Rogers A. (2005). Training adult literacy educators in developing countries: Background paper prepared for the Education for All Global Monitoring Report 2006.

Rogers, A. (2002). Teaching adults, (3rd ed). Philadelphia, PA: Open University Press. 
Rogers, A.(2006). DFID Experience of adult literacy. International Journal of Educational Development 26, 339-346.

St. Clair, R. (2002). Andragogy revisited: Theory for the 21st century myths and realities. http://www.cete.org/acve/testonly/docgen.asp? tbl-mr\&id=109

Surakhmad, (2009). Focus on adult illiteracy in Indonesia improving or relapse. Retrieved through: Focus on Adult illiteracy in Indonesia Improving or relapse.

Tough A. (1978). Major Learning Efforts: Recent Research and Future Directions. Adult Education Quarterly, 28, 250-263

Vodde, R.F. (2008). The efficacy of an andragogical instructional methodology in basic police training and education. (PhD Thesis). University of Leicester.

Wagner, D.A. (2000). EFA 2000 thematic study on literacy and adult education: For presentation at the world education forum, Dakar. International Literacy Institute, 91-95.

\section{Citation of this Article:}

Niwaz, A., Ahmed, A., \& Zaman, A. (2017). Causes of relapse into illiteracy of adult female neo-literates: An evaluation. Pakistan Journal of Education, 34(1), 21-34.

Received on: 21 Sep, 2016

Revised on: 27 April, 2017

Accepted on: 2 June, 2017 